\title{
On Linkage of Parallel Biserial Servers Linked with a Common Server to a Three Stage Flowshop Scheduling Model
}

\author{
Deepak Gupta, Sameer Sharma, and Seema Sharma
}

\begin{abstract}
The present paper deals with the linkage between a queue network in which a common service server is linked in series with each of two parallel biserial servers and a three stage flowshop scheduling system. The objective of this paper is of two folds, on one hand it finds mean queue length and the total waiting time of jobs and on other hand it minimizes the total elapsed time. The proposed model provides an important tool for manufacturing concern, office management, banking service system, computer networks and in administrative setup etc.
\end{abstract}

Index Terms-Queue network, flowshop, mean queue length, waiting time, processing time, biserial channels, makespan.

\section{INTRODUCTION}

A lot of research work has already been done separately in the field of Queueing and Scheduling theory as per literature review. Only some efforts have been made so far to combine these two systems. Johnson (1954) gave a procedure for finding the optimal schedule to minimize the total elapsed time in two and three stage flowshop scheduling. Jackson (1954) studied the behavior of a queuing system containing phase type service. Maggu (1970) studied a network of two queues in biseries to find the total idle time of the jobs/customers which corresponds to a practical situation arises in the production concern. Singh, T.P. et al. (2005) studied the different aspects of the various queuing and scheduling models with various parameters. Singh, T.P. and K. Vinod (2009) studied the linkage of queuing system to a flow shop scheduling model.

Recently Gupta and Sharma (2012) made an attempt to link a parallel biserial queue network linked with a common server to a flow shop scheduling model. This paper is further an extension of the study made by Gupta and Sharma (2012) by establishing a linkage between a queuing network involving biserial servers linked with a common server to a flowshop system involving three machines. Therefore the present paper establishes a bridge between a network of queue model given by Singh, T.P. and Kumar Vinod (2009) and the three stage scheduling system given by Johnson (1954).

Manuscript received March 14, 2012; revised April 23, 2012.

D. Gupta is with Department of Mathematics, M.M. University, Mullana, Ambala, India (email:seemasharma7788@yahoo.com).

S. Sharma and S. Sharma are with Department of Mathematics, D.A.V. College, Jalandhar, Punjab, India.

\section{Practical SitUATION}

Various practical situations of this model arise in manufacturing concern, office management, banking service system, computer networks, administrative setup etc. For example, we can consider a network of such a system in a production concern in which three machines are linked serially with a network of queues comprised of three service servers, one of them is commonly linked in series with each of other two parallel servers in biseries. For example, we can consider two parallel biserial servers one for cutting and other for turning. Some jobs after cutting may go to turning and vice-versa. Both these servers are commonly connected to the server for chroming / polishing. After that the jobs has to passed thought three machine taken as finishing the jobs/goods, inspection of quality of goods produced and third machine for the final packing. After completing the service jobs/goods come out from the network.

\section{MATHEMATICAL MODEL}

Considered a queue network comprised of three service servers $S_{1}, S_{2}$ and $S_{3}$, where the servers $S_{1}, S_{2}$ are parallel biserial servers connected in series with a common server $S_{3}$ and which is further linked with a flowshop scheduling model consisting of three machines $\mathrm{M}_{1}, \mathrm{M}_{2}$ and $\mathrm{M}_{3}$. The customers/jobs demanding service arrive in Poisson streams at the servers $S_{1}$ and $S_{2}$ with mean arrival rate $\lambda_{1}, \lambda_{2}$ and mean service rate $\mu_{1}$ and $\mu_{2}$ respectively. Let $\mu_{3}$ be the mean service rate for the server $S_{3}$. Queues $Q_{1}, Q_{2}$ and $Q_{3}$ are said to be formed in front of the channels $S_{1}, S_{2}$ and $S_{3}$ respectively, if they are busy.

Customers/Jobs coming at the rate $\lambda_{1}$ either go to the network of servers $S_{1} \rightarrow S_{2} \rightarrow S_{3} \quad$ or $\quad S_{1} \rightarrow S_{3} \quad$ with probabilities $p_{12}, p_{13}$ such that $p_{12}+p_{13}=1$ and those coming at rate $\lambda_{2}$ either goes to the network of the servers $S_{2} \rightarrow S_{1} \rightarrow S_{3}$ or $S_{2} \rightarrow S_{3}$ with probabilities $p_{21}, p_{23}$ such that $p_{21}+p_{23}=1$. Further the completion time( waiting time + service time) of customers / jobs through $\mathrm{Q}_{1}, \mathrm{Q}_{2} \& \mathrm{Q}_{3}$ form the setup times for machine $\mathrm{M}_{1}$.After coming out from the server $\mathrm{S}_{3}$.i.e. through Phase I, customers / jobs go to the machines $\mathrm{M}_{1}, \mathrm{M}_{2}$ and $\mathrm{M}_{3}$ (in Phase II) for processing with processing time $A_{i 1}, A_{i 2}$ and $A_{i 3}$. Our objective is to develop a heuristic algorithm to find an optimal sequence of the jobs / customers with minimum makespan in this QueueScheduling linkage system. 


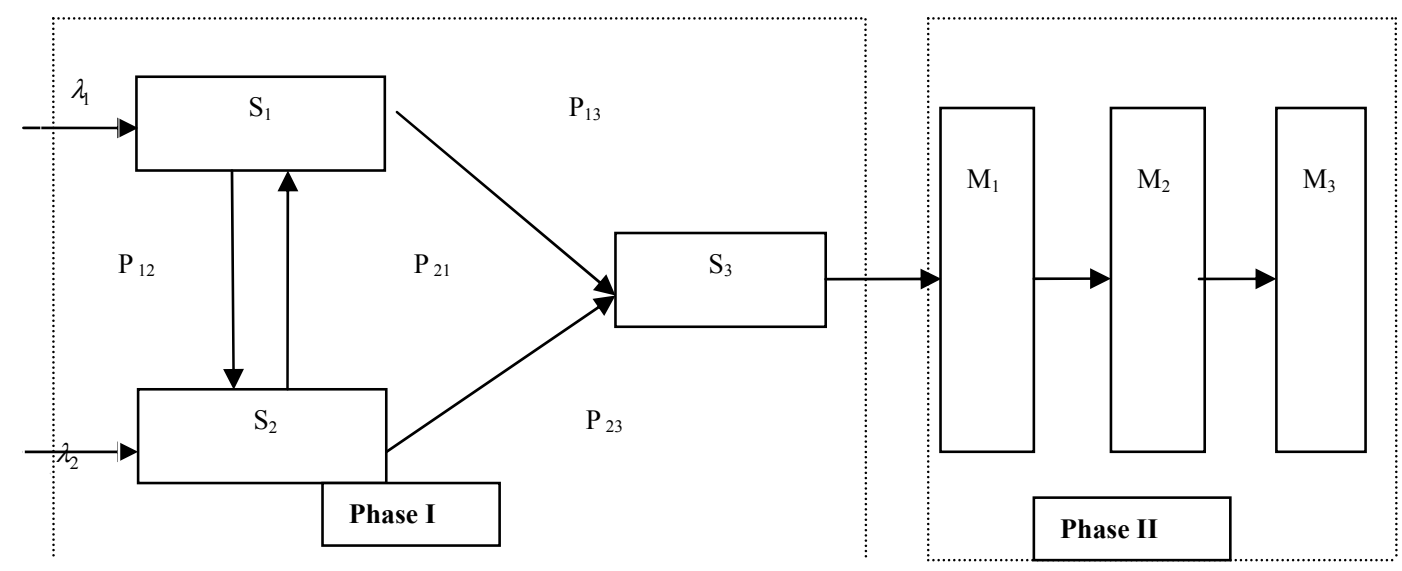

Fig. 1. Queuing network model.

\section{ASSUMPTIONS}

1. We assume that the arrival rate in the queue network follows Poisson distribution.

2. Each job / customer is processed on all the machines $\mathrm{M}_{1}$, $\mathrm{M}_{2}$ and $\mathrm{M}_{3}$ in the same order and pre-emission is not allowed, i.e. once a job is started on a machine, the process on that machine can not be stopped unless job is completed.

3. For the existence of the steady state behaviour the following conditions hold good:

$$
\begin{aligned}
& \text { (i) } \rho_{1}=\frac{\left(\lambda_{1}+\lambda_{2} p_{21}\right)}{\mu_{1}\left(1-p_{12} p_{21}\right)}<1, \\
& \text { (ii) } \rho_{2}=\frac{\left(\lambda_{2}+\lambda_{1} p_{12}\right)}{\mu_{2}\left(1-p_{12} p_{21}\right)}<1 \\
& \text { (iii) } \rho_{3}=\frac{p_{13}\left(\lambda_{1}+\lambda_{2} p_{21}\right)+p_{23}\left(\lambda_{2}+\lambda_{1} p_{12}\right)}{\mu_{2}\left(1-p_{12} p_{21}\right)}<1 .
\end{aligned}
$$

\section{ALGORITHM}

The following algorithm provides the procedure to determine the optimal sequence of the jobs to minimize the flow time of machines $\mathrm{M}_{1}, \mathrm{M}_{2}$ and $\mathrm{M}_{3}$ when the completion time (waiting time + service time) of the jobs coming out of Phase $I$ is the setup times for the machine $M_{1}$.

Step 1: Find the mean queue length on the lines of Singh \& Kumar (2005) using the formula

$$
\begin{aligned}
& L=\frac{\rho_{1}}{1-\rho_{1}}+\frac{\rho_{2}}{1-\rho_{2}}+\frac{\rho_{3}}{1-\rho_{3}} \\
& \text { Here } \rho_{1}=\frac{\left(\lambda_{1}+\lambda_{2} p_{21}\right)}{\mu_{1}\left(1-p_{12} p_{21}\right)}, \\
& \rho_{2}=\frac{\left(\lambda_{2}+\lambda_{1} p_{12}\right)}{\mu_{2}\left(1-p_{12} p_{21}\right)} \\
& \rho_{3}=\frac{p_{13}\left(\lambda_{1}+\lambda_{2} p_{21}\right)+p_{23}\left(\lambda_{2}+\lambda_{1} p_{12}\right)}{\mu_{2}\left(1-p_{12} p_{21}\right)} ;
\end{aligned}
$$

$\lambda_{i}$ is the mean arrival rate, $\mu_{i}$ is the mean service rate, $p_{i j}$ are the probabilities.

Step 2: Find the average waiting time of the customers on the line of Little's (1961) using relation $E(w)=\frac{L}{\lambda}$, where $\lambda=\lambda_{1}+\lambda_{2}$.

Step 3: Find the completion time(C) of jobs / customers coming out of Phase I, .i.e. when processed thought the network of queues $\mathrm{Q}_{1}, \mathrm{Q}_{2}$ and $\mathrm{Q}_{3}$ by using the formula $C=E(W)+\frac{1}{\mu_{1} p_{12}+\mu_{1} p_{13}+\mu_{2} p_{21}+\mu_{2} p_{23}+\mu_{3}}$.

Step 4: The completion time $C$ of the customers / jobs through the network of queues $\mathrm{Q}_{1}, \mathrm{Q}_{2}$ and $\mathrm{Q}_{3}$ will be the setup time for machine $\mathrm{M}_{1}$. Define the three machines $\mathrm{M}_{1}$, $\mathrm{M}_{2}$ and $\mathrm{M}_{3}$ with processing time $A_{i 1}^{\prime}=A_{i 1}+C, A_{i 2}$ and $A_{i 3}$.

Step 5: Check the condition: either $\operatorname{Min} A_{i 1}^{\prime} \geq \operatorname{Max} A_{i 2}$ or $\operatorname{Min} A_{i 3} \geq \operatorname{Max} A_{i 2}$ or Both for all $i$.

If the conditions are satisfied then go to Step 6, else the data is not in the standard form.

Step 6: Introduce the two fictitious machines $\mathrm{G}$ and $\mathrm{H}$ with processing times $G_{i}$ and $H_{i}$ as

$$
G_{i}=A_{i 1}^{\prime}+A_{i 2} \text { and } H_{i}=A_{i 2}+A_{i 3} \text { for all } i \text {. }
$$

Step 7: Apply Johnson's (1954) procedure to find the optimal sequence(s) with minimum elapsed time.

Step 8: Prepare In-Out tables for the optimal sequence(s) obtained in step 7. The sequence $S_{k}$ having minimum total elapsed time will be the optimal sequence for the given problem.

\section{NUMERICAL ILLUSTRATION}

Consider eight customers/jobs are processed through the network of three queues $Q_{1}, Q_{2}$ and $Q_{3}$ with the servers $S_{1}, S_{2}$ and $S_{3}$, where $S_{3}$ is commonly linked in series with each of the two parallel biserial servers $S_{1}$ and $S_{2}$. Let the number of the customers, mean arrival rate, mean service rate and associated probabilities are given as follows:

After completing the service at Phase-I, jobs / customers go to the machines $M_{1}, M_{2}$ and $M_{3}$ with processing time $A_{i l}$, $A_{i 2}$ and $A_{i 3}$ respectively given as follows: 
TABle I: No. of Customers, Mean Arrival Rate, Mean Service RATE WITH PROBABILITIES

\begin{tabular}{|c|c|c|c|c|}
\hline S. No & $\begin{array}{c}\text { No. of } \\
\text { Customers }\end{array}$ & $\begin{array}{c}\text { Mean Arrival } \\
\text { Rate }\end{array}$ & $\begin{array}{c}\text { Mean Service } \\
\text { Rate }\end{array}$ & Probabilities \\
\hline 1 & $\mathrm{n}_{1}=5$ & $\lambda_{1}=5$ & $\mu_{1}=12$ & $\mathrm{p} 12=0.4$ \\
\hline 2 & $\mathrm{n}_{2}=3$ & $\lambda_{2}=4$ & $\mu_{2}=9$ & $\mathrm{p} 13=0.6$ \\
\hline & & & $\mu_{3}=10$ & $\mathrm{p} 21=0.5$ \\
\hline & & & & $\mathrm{p} 23=0.5$ \\
\hline
\end{tabular}

TABLE II: PROCESSING TIMES FOR THE MACHINES $M_{1}, M_{2}$ AND $M_{3}$

\begin{tabular}{|c|c|c|c|c|c|c|c|c|}
\hline Jobs & 1 & 2 & 3 & 4 & 5 & 6 & 7 & 8 \\
\hline $\mathrm{M}_{1}\left(\mathrm{~A}_{\mathrm{i} 1}\right)$ & 5 & & & 10 & & & & \\
\hline $\mathrm{M}_{2}\left(\mathrm{~A}_{\mathrm{i} 2}\right)$ & 8 & & & & & & & \\
\hline $\mathrm{M}_{3}\left(\mathrm{~A}_{\mathrm{i} 3}\right)$ & 10 & & & & & & & \\
\hline
\end{tabular}

The objective is to find an optimal sequence of the jobs / customers to minimize the makespan in this Queue Scheduling linkage system by considering the first phase service into account.

Solution: We have

$$
\begin{aligned}
& \rho_{1}=\frac{\lambda_{1}+\lambda_{2} p_{21}}{\left(1-p_{12} p_{21}\right) \mu_{1}}=\frac{7}{9.6}, \\
& \rho_{2}=\frac{\lambda_{2}+\lambda_{1} p_{12}}{\left(1-p_{12} p_{21}\right) \mu_{2}}=\frac{6}{7.2}, \\
& \rho_{3}=\left[\frac{\left(\lambda_{1}+\lambda_{2} p_{21}\right) p_{13}+\left(\lambda_{2}+\lambda_{1} p_{12}\right) p_{23}}{\mu_{3}\left(1-p_{12} p_{21}\right)}\right]=\frac{7.2}{8.8} .
\end{aligned}
$$

Mean Queue Length $=$ Average number of Jobs / Customers $=L=\frac{\rho_{1}}{1-\rho_{1}}+\frac{\rho_{2}}{1-\rho_{2}}+\frac{\rho_{3}}{1-\rho_{3}}=12.2692$

Average waiting time of the jobs / customers $=$ $E(w)=\frac{L}{\lambda}=\frac{12.2692}{9}=1.3632$.

The total completion time of Jobs / Customers when processed through queue network in Phase I

$$
=\quad C=E(W)+\frac{1}{\mu_{1} p_{12}+\mu_{1} p_{13}+\mu_{2} p_{21}+\mu_{2} p_{23}+\mu_{3}}
$$

$$
=1.3632+\frac{1}{4.8+7.2+4.5+4.5+11}=1.39445 \approx 1.39 \text {. }
$$

On taking the completion time $\mathrm{C}=1.39$ as the setup time, when jobs / customers came for processing with machine $M_{1}$. The new reduced two machine problem with processing time $A_{i 1}^{\prime}=A_{i 1}+C, A_{i 2}$ and $A_{i 3}$ on machine $M_{1}, M_{2}$ and $M_{3}$ is as shown :

TABLE III: MOdIFIED PROCESSING TIMES OF THE MACHINES

\begin{tabular}{|c|c|c|c|c|c|c|c|c|}
\hline Jobs & 1 & 2 & 3 & 4 & 5 & 6 & 7 & 8 \\
\hline $\mathrm{M}_{1}\left(\mathrm{~A}_{\mathrm{i} 1}\right)$ & 6.39 & 8.39 & 9.39 & 11.39 & 7.39 & 13.39 & 10.39 & 8.39 \\
\hline $\mathrm{M}_{2}\left(\mathrm{~A}_{\mathrm{i} 2}\right)$ & 8 & 7 & 8 & 6 & 5 & 6 & 4 & 7 \\
\hline $\mathrm{M}_{3}\left(\mathrm{~A}_{\mathrm{i} 3}\right)$ & 10 & 8 & 9 & 8 & 9 & 10 & 9 & 8 \\
\hline
\end{tabular}

The two fictitious machines $\mathrm{G}$ and $\mathrm{H}$ with processing times $G_{i}$ and $H_{i}$ are as follows

TABLE IV: TwO FICTIOUS MACHINES WITH PROCESSING TIMES

$$
G_{i} \text { AND } H_{i}
$$

\begin{tabular}{|c|c|c|c|c|c|c|c|c|}
\hline Jobs & 1 & 2 & 3 & 4 & 5 & 6 & 7 & 8 \\
\hline $\mathrm{Gi}$ & 14.39 & 15.39 & 17.39 & 17.39 & 12.39 & 19.39 & 14.39 & 15.39 \\
\hline $\mathrm{Hi}$ & 18 & 15 & 17 & 14 & 14 & 16 & 13 & 15 \\
\hline
\end{tabular}

By Johnson's (1954) procedure the optimal sequence is $\mathrm{S}$ $=5-1-2-8-3-6-4-7$.

The In-Out Table for the optimal sequence $\mathrm{S}$ is

TABLE V: IN-OUT FLOW TABLE

\begin{tabular}{|c|c|c|c|}
\hline Jobs & M1 & M2 & M3 \\
\hline 5 & $0.0-7.39$ & $7.39-12.39$ & $12.39-21.39$ \\
\hline 1 & $7.39-13.78$ & $13.78-21.78$ & $21.78-31.78$ \\
\hline 2 & $13.78-20.78$ & $21.78-28.78$ & $31.78-39.78$ \\
\hline 8 & $20.78-29.17$ & $29.17-36.17$ & $39.78-37.78$ \\
\hline 3 & $29.17-38.56$ & $38.56-46.56$ & $46.56-55.56$ \\
\hline 6 & $38.56-51.92$ & $51.92-57.92$ & $57.92-67.92$ \\
\hline 4 & $51.92-63.31$ & $63.31-69.31$ & $69.31-77.31$ \\
\hline 7 & $63.31-73.3$ & $73.30-77.3$ & $77.31-86.31$ \\
\hline
\end{tabular}

Hence total elapsed time is 86.31 units and Mean queue length is 12.2692 units.

\section{CONCLUSION}

The present paper establishes a bridge between a queuing network consisting of parallel biserial servers linked in series with a common server and a three stage flow shop scheduling system. The model discussed here provides an important tool for the decision makers in industrial/production concern, in banking services, in computer networks etc where we have to minimize the average waiting time and flow time of the jobs/customers simultaneously. The study can further be extended by introducing more complex queueing networks and various other constraints in the flow shop system of machines.

\section{REFERENCES}

[1] S. M. Johnson, "Optimal two and three stage production schedule with setup time included," Nav. Res. Log. Quartz., vol. 1, no.1, pp. 61-68, 1954.

[2] R. R. P. Jackson, "Queuing system with phase type service," $O . R$. Quat., no. 5, pp. $109-120,1954$.

[3] J. D. C. Little, "A proof of the queuing formula: $L=W \lambda$," Operations Research, vol. 9, no. 3, pp. 383-387, 1961.

[4] P. L. Maggu, "Phase type service queue with two servers in Biseries," J. Op. Res. Soc. Japan, vol. 13, no. 1, 1970.

[5] T. P. Singh, "On some networks of queuing \& scheduking system. Ph.D Thesis," Garhwal University. 1986, Shrinagar, Garhwal.

[6] T. P. Singh, V. Kumar, and R. Kumar, "On transient behaviuor of a queuing network with parallel biserial queues," JMASS. Pp. 68 -75, 2005. 
[7] P. L. Maggu and S. Gupta, "On a network of two queues in bitandem linked in series with a network of two machines in flowshop," JISSOR, vol. XXVII, no. 1-4, pp. $11-15,2006$

[8] C. Narain, "Special models in flowshop sequencing problems," $\mathrm{Ph} . \mathrm{D}$ Thessis. 2006, University of Delhi.

[9] T. P. Singh and V. Kumar, "On linkage of queuing system to a flowshop scheduling system," International Journal of Agriculture and Stat. Sci., vol. 3, no. 2, pp. $571-576,2007$.
[10] P. L. Maggu, T. P. Singh, and V. Kumar, "A note on serial queuing \& scheduling linkage,” PAMS, vol. LXV, no. 1-2, pp. 177-178, 2007.

[11] V. Kumar and T. P.Singh, "On linkage of a scheduling system with biserial queue network," $A B J M I$, vol. 1, no. 1-2, pp. 71-76, 2009.

[12] D. Gupta, S. Sharma, and Seema, "On linkage of a flowshop scheduling model including job block criteria with a parrallel biserial queue network," Computer Engineering \& Intelligent System, vol. 3, no. 2 , pp. $17-28,2012$. 